\title{
Consumo de forragem por novilhas de corte recebendo farelo de arroz com e sem ionóforo
}

\author{
Forage intake by beef heifers receiving rice bran with and without ionophore
}

\author{
Lidiane Raquel Eloy ${ }^{I}$ Marta Gomes da Rocha ${ }^{I^{*}}$ Luciana Pötter $^{\mathrm{I}}$ \\ Álvaro Moraes da Fonseca Neto ${ }^{\mathrm{I}}$ Ludmila Leonardi Biscaíno ${ }^{\mathrm{I}}$ Marcos Bernardino Alves $^{\mathrm{I}}$ \\ Larissa Arnhold Graminho ${ }^{\mathrm{I}}$ Sheila Cristina Bosco Stivanin ${ }^{\mathrm{I}}$
}

\section{RESUMO}

O consumo de forragem foi avaliado em novilhas de corte exclusivamente em pastagem de azevém (Lolium multiflorum Lam.) ou recebendo farelo de arroz integral (FAI) com ou sem adição de ionóforo. Foi usado o óxido de cromo como indicador da produção fecal. $O$ delineamento experimental foi o inteiramente casualizado, com medidas repetidas no tempo, com três tratamentos e três repetições de área. Os animais foram considerados as unidades experimentais nas avaliações de consumo. $O$ consumo de pasto pelas novilhas foi similar nos diferentes sistemas alimentares, ocasionando taxa de lotação semelhante. $O$ fornecimento de farelo de arroz integral, com ou sem monensina, aumenta o consumo de matéria seca total. A adição de ionóforo ao FAI aumenta o desempenho individual das novilhas, sendo o seu uso recomendado quando existe o objetivo de reduzir a sua idade ao primeiro acasalamento.

Palavras-chave: Angus, Lolium multiflorum Lam., monensina, óxido de cromo.

\section{ABSTRACT}

The forage intake was evaluated in beef heifers exclusively in Italian ryegrass (Lolium multiflorum Lam.) pasture or receiving rice bran with or without addition of ionophore. Chromic oxide was used as a fecal production indicator. The experimental design was completely randomized with repeated measures on time, three treatments and three area replicates. The animals were considered experimental units for intake evaluations. The pasture intake by heifers was similar at different feeding systems causing similar stocking rate. The supply of rice bran with or without monensin increased the total dry matter intake. The individual heifers performance was increased with ionophore addition to rice bran. Ionophore is recommended when there is a goal to reduce the age of beef heifers at their first mating.

Key words: Angus, Lolium multiflorum Lam., monensin, chromic oxide.

\section{INTRODUÇÃO}

O consumo voluntário de forragem é o principal fator que influencia a produtividade dos sistemas em pastejo, sendo influenciado por características relacionadas ao animal, à planta, ao suplemento fornecido, ao ambiente e ao manejo imposto ao pasto. O consumo total de matéria seca é menor em ruminantes mantidos exclusivamente em pastejo, em relação aos que recebem suplementos, e é esperado melhor desempenho de bovinos de alta produção quando há inclusão de suplementos em sua dieta, permitindo que esses expressem seu potencial genético. ROSA et al. (2013), no entanto, não observaram mudança na ingestão total de matéria seca, independente do estádio de desenvolvimento do pasto, quando novilhas receberam grão de milho ou gordura extrusada em pastagem de azevém (Lolium multiflorum Lam.).

Dentre os suplementos que podem ser utilizados para animais em pastejo em azevém, destaca-se o farelo de arroz integral (FAI), por sua abundância regional. No Rio Grande do Sul, na safra 2011/12, estima-se que tenham sido produzidas aproximadamente 680 mil toneladas desse subproduto. Respostas anteriores, obtidas com o uso do FAI na recria de novilhas de corte, em pastagem de inverno, mostram que, quando associado à polpa cítrica (1:1), proporcionou incrementos de $21,92 \%$ no ganho médio diário e $46,01 \%$ na taxa de lotação, em relação ao uso exclusivo da pastagem (FRIZZO et al., 2003).

\footnotetext{
'Programa de Pós-graduação em Zootecnia, Universidade Federal de Santa Maria (UFSM), Av. Roraima, 1000, Prédio 42, 97105-900,
} Santa Maria, RS, Brasil. E-mail: mgdarocha@gmail.com.*Autor para correspondência. 
Desde meados dos anos 70, os ionóforos, dentre eles a monensina, vêm sendo utilizados em dietas para bovinos para melhorar a eficiência alimentar e o ganho médio diário. Dentre os efeitos da monensina está o de reduzir o crescimento de bactérias gram-positivas, aumentando a proporção de ácido propiônico em relação aos ácidos acético e butírico (DUFFIELD et al., 2012).

Face à importância do FAI como suplemento energético para bovinos e à inexistência de dados sobre o seu uso, associado com a monensina, esse trabalho foi realizado com o objetivo de avaliar a ingestão de matéria seca por novilhas de corte em pastagem exclusiva de azevém, ou recebendo farelo de arroz integral como suplemento, com e sem adição de ionóforo.

\section{MATERIAL E MÉTODOS}

O experimento foi desenvolvido na Universidade Federal de Santa Maria, de agosto a outubro de 2011, na região fisiográfica denominada Depressão Central do Rio Grande do Sul. O clima da região é $\mathrm{Cfa}$, subtropical úmido, segundo a classificação de Köppen. Foram utilizadas 45 novilhas da raça Angus, com idade e peso inicial de oito meses e $145,10 \pm 12,30 \mathrm{~kg}$. As novilhas permaneceram em pastagem exclusiva de azevém (Lolium multiflorum Lam.) ou recebendo $0,80 \%$ do peso corporal (PC) de farelo de arroz integral, com ou sem adição de $200 \mathrm{mg}$ animal $^{-1} \mathrm{dia}^{-1}$ de monensina sódica.

A pastagem de azevém foi estabelecida no dia quatro de maio de 2011, com preparo mínimo do solo, numa área de 7,20ha, com nove subdivisões. Foram utilizados $45 \mathrm{~kg} \mathrm{ha}^{-1}$ de sementes e $250 \mathrm{~kg} \mathrm{ha}^{-1}$ de adubo N-P-K, da fórmula 05-20-20. A quantidade de nitrogênio $(\mathrm{N})$ aplicado em cobertura foi de $67 \mathrm{~kg}$ $\mathrm{ha}^{-1}$, na forma de ureia. O farelo de arroz $(92,03 \%$ de matéria seca (MS), $10,11 \%$ de matéria mineral (MM), 89,89\% de matéria orgânica (MO), 25,79\% de fibra em detergente neutro (FDN), $12,45 \%$ de extrato etéreo (EE), 13,80\% de proteína bruta (PB) e 84,62\% de digestibilidade in situ da matéria seca (DISMS)), com adição de $4 \%$ de calcário calcítico, foi fornecido diariamente, às $14 \mathrm{~h}$.

$\mathrm{O}$ método de pastejo foi o contínuo, com número variável de animais. A massa de forragem foi avaliada a cada quatorze dias, por meio da técnica de estimativa visual com dupla amostragem. Na mesma ocasião, foi medida a altura do dossel, nos mesmos pontos utilizados para estimativa da MF. A forragem proveniente dos cortes foi homogeneizada e dividida em duas subamostras, para determinação do teor de MS e dos componentes estruturais do azevém, por meio da separação manual. Após a separação botânica e secagem dos componentes estruturais em estufa com circulação forçada de ar a $55^{\circ} \mathrm{C}$, por $72 \mathrm{~h}$, foi determinado o teor de MS e a participação em $\mathrm{kg}$ de MS de lâminas foliares, colmos, material senescente e inflorescência. A partir da proporção de lâminas foliares e colmos, foi determinada a relação lâmina:colmo.

A pesagem dos animais foi realizada a cada 28 dias, com jejum prévio de sólidos e líquidos de 12 horas. $\mathrm{O}$ ganho médio diário $\left(\mathrm{kg}\right.$ animal $\left.{ }^{-1} \mathrm{dia}^{-1}\right)$ foi determinado em períodos de 28 dias. Para o cálculo da taxa de lotação ( $\mathrm{kg}$ de $\mathrm{PC} \mathrm{ha}{ }^{-1}$ ), foi utilizado o somatório do peso médio dos animais-teste, com o peso médio de cada animal regulador multiplicado pelo número de dias que o mesmo permaneceu no piquete, dividido pelo número de dias do período. A oferta de forragem (OF) foi calculada por meio do quociente entre a disponibilidade de forragem e a taxa de lotação, expressa em kg de MS $100 \mathrm{~kg}$ de $\mathrm{PC}^{-1}$. A oferta de lâminas foliares verdes (OFL) foi obtida por meio da multiplicação da OF pelo percentual de lâminas foliares na MF. Por meio da técnica da simulação de pastejo, foram tomadas amostras de forragem para determinação de suas características químicas. Nessas amostras, foi determinado o teor de MS, MO e MM (AOAC, 1995). Os teores de FDN e PB foram determinados de acordo com ROBERTSON \& VAN SOEST (1981). A DISMS foi determinada por técnica descrita por ØRSKOV \& MCDONALD (1979). A concentração de EE foi determinada em um sistema de refluxo. $O$ teor de nutrientes digestíveis totais (NDT) foi determinado de acordo com KUNKLE \& BATES (1998).

A avaliação da ingestão de forragem foi realizada nos períodos: 08 a 19/08/2011; 05 a 16/09/2011 e 03 a 14/10/2011, para coincidir com as demais avaliações do pasto e dos animais. Foi utilizado óxido de cromo $\left(\mathrm{Cr}_{2} \mathrm{O}_{3}\right)$ como indicador externo da produção fecal e o período de fornecimento foi de 12 dias (oito dias para adaptação e quatro dias para coleta fecal). A dosificação foi feita, por via oral, fornecendo-se diariamente, às $12 \mathrm{~h}$, dez gramas de óxido de cromo por bezerra. O nível de cromo nas fezes secas foi determinado por espectrofotometria de absorção atômica pela técnica adaptada por KOZLOSKI et al. (1998). Para estimar a produção fecal, foi utilizada a fórmula: $\mathrm{PF}=$ cromo administrado ( $\mathrm{g} \mathrm{dia}^{-1}$ ) cromo nas fezes ${ }^{-1}\left(\mathrm{~g} \mathrm{~kg}^{-1}\right.$ de MS) (POND et al., 1989). Avaliou-se o consumo de MS (IMS, g dia-1) pela fórmula: IMS forragem $=(\mathrm{MS}$ fecal total $-(\mathrm{CMS}$ suplemento*(1-digestibilidade do suplemento))/ (1-digestibilidade da forragem) e a ingestão de MS em porcentagem do peso corporal (IPC). A partir 
desses dados, foram calculados o consumo total, consumo de forragem, consumo de FDN, consumo de EM e o consumo de PB, em \% do PC. Foi calculada a quantidade consumida de suplemento $\mathrm{kg}$ de peso metabólico $^{-1}$ (PM) individualmente, por meio da equação: (consumo de suplemento em $\mathrm{kg} * 1000$ )/peso corporal $^{* 0,75}$. Foi observada a atividade de pastejo dos três animais-teste de cada piquete, em seis ciclos de 10 estações alimentares cada um e, a partir desses dados, foi calculado o número de estações alimentares visitadas por minuto.

O delineamento experimental foi 0 inteiramente casualizado, com medidas repetidas no tempo, com três sistemas alimentares e três repetições de área. Para as avaliações do pasto, os piquetes foram considerados as unidades experimentais. Para as avaliações de consumo de forragem, os animais foram considerados as unidades experimentais, com seis repetições em cada sistema alimentar, sendo dosificados dois animais por piquete. Utilizouse um modelo misto com o efeito fixo de sistemas alimentares, períodos de avaliação e suas interações e os efeitos aleatórios do resíduo e de novilhas aninhadas nos sistemas alimentares, utilizando o procedimento MIXED. Quando observadas diferenças, as médias foram comparadas pelo recurso lsmeans. Foram realizados testes de seleção da estrutura, utilizando o critério de informação bayesiano (BIC), para determinar o modelo que melhor representasse os dados. A interação entre sistemas alimentares e períodos de avaliação foi desdobrada quando significativa a $10 \%$ de probabilidade e as respostas das variáveis em função dos dias de utilização da pastagem, modeladas utilizando-se função polinomial até terceira ordem.

\section{RESULTADOS E DISCUSSÃO}

Não houve interação $(\mathrm{P}>0,10)$ entre sistemas alimentares e períodos de avaliação para as variáveis do pasto. As bezerras, nos diferentes sistemas alimentares $(\mathrm{P}>0,10)$, pastejaram em piquetes com similar massa de forragem (MF) $\left(1576,87 \pm 161,05 \mathrm{~kg}\right.$ ha de $\left.\mathrm{MS}^{-1}\right)$, altura do dossel $(10,14 \pm 0,83 \mathrm{~cm})$, oferta de forragem $(9,94 \pm 0,71 \%)$, oferta de lâminas foliares (OFL) $(4,50 \pm 0,61 \%)$. Na forragem colhida por simulação de pastejo, os teores de fibra em detergente neutro (FDN) $(50,72 \pm 0,61 \%)$ e nutrientes digestíveis totais (NDT) $(79,46 \pm 0,62 \%)$ foram semelhantes, assim como a digestibilidade in situ da matéria seca (DISMS) $(79,22 \pm 1,48 \%)$. Essas variáveis apresentaram diferença $(\mathrm{P}<0,10)$ entre períodos de avaliação do azevém (Tabela 1).

Houve interação entre sistemas alimentares e períodos de avaliação para o teor de $\mathrm{PB}$ na forragem proveniente da simulação de pastejo $(\mathrm{P}<0,10)$. Foi observado comportamento linear decrescente, em função dos dias de utilização, para o teor de PB na forragem aparentemente consumida ( $\hat{Y}=26,43-0,08 x ; P<0,0001 ; r^{2}=65,22 \% ; C V=6,49 \%$ ), quando as novilhas estiveram exclusivamente em pastejo ou receberam FAI. Quando as novilhas receberam FAI mais ionóforo, o teor de $\mathrm{PB}$ não se ajustou a nenhum modelo de regressão, com valor médio de $22,97 \pm 2,44 \%$. Considerando que a relação lâmina:colmo ( $\hat{\mathrm{Y}}=5,86-0,06 \mathrm{x} ; \mathrm{P}<0,0001 ; \mathrm{r}^{2}=85,76 \%$; $\mathrm{CV}=28,35 \%)$ e oferta de lâminas foliares $(\hat{\mathrm{Y}}=15,13$ 0,09x; $\left.\quad \mathrm{P}<0,0001 ; \quad \mathrm{r}^{2}=55,94 \% ; \quad \mathrm{CV}=19,98 \%\right)$ reduziram-se no decorrer da utilização da pastagem, a inclusão de monensina na dieta das novilhas, no que diz respeito ao teor de $\mathrm{PB}$ na forragem, as tornou independentes dessas mudanças na disponibilidade de lâminas foliares, onde há maior concentração de

Tabela 1 - Características e composição química do pasto provenientes da simulação de pastejo nos diferentes períodos de avaliação do azevém.

\begin{tabular}{|c|c|c|c|c|c|c|}
\hline \multirow{2}{*}{ Variáveis } & \multicolumn{3}{|c|}{--------- Períodos de Avaliação --------- } & \multirow{2}{*}{$\mathrm{P} *$} & \multirow{2}{*}{$\mathrm{P}^{* *}$} & \multirow{2}{*}{$\mathrm{CV}$} \\
\hline & 03/08-30/08 & $31 / 08-27 / 09$ & $28 / 09-25 / 10$ & & & \\
\hline Altura do dossel ${ }^{1}$ & $9,01 \mathrm{~b}$ & $9,46 \mathrm{~b}$ & $11,97 \mathrm{a}$ & 0,0003 & 0,2180 & 5,65 \\
\hline Oferta de forragem ${ }^{2}$ & $11,68 \mathrm{a}$ & $10,84 \mathrm{a}$ & $6,64 \mathrm{~b}$ & 0,0019 & 0,2761 & 6,99 \\
\hline Oferta de lâminas foliares ${ }^{3}$ & $7,11 \mathrm{a}$ & $4,50 \mathrm{~b}$ & $1,36 \mathrm{c}$ & 0,0004 & 0,9135 & 13,48 \\
\hline Fibra em detergente neutro ${ }^{3}$ & $42,80 \mathrm{c}$ & $49,33 b$ & $60,03 a$ & $<, 0001$ & 0,2719 & 1,20 \\
\hline Nutrientes digestíveis totais ${ }^{3}$ & $82,31 \mathrm{a}$ & $82,13 \mathrm{a}$ & $73,95 b$ & $<, 0001$ & 0,6056 & 0,78 \\
\hline Digestibilidade in situ da matéria seca ${ }^{3}$ & $85,30 \mathrm{a}$ & $81,66 a$ & $70,90 \mathrm{~b}$ & $<, 0001$ & 0,4091 & 1,87 \\
\hline
\end{tabular}

*Probabilidade entre períodos de avaliação do azevém; **Probabilidade da interação sistemas alimentares e períodos de avaliação (P<0,10); $\mathrm{CV}=$ coeficiente de variação; ${ }^{1}-\mathrm{cm} ;{ }^{2}-\%$ do peso corporal; ${ }^{3}-\%$. Valores seguidos de letras distintas na linha indicam diferença pelo Ismeans a $10 \%$ de probabilidade. 
nitrogênio. Esse teor é 58,86\% acima das exigências de PB para essa categoria, que é de 13,52\% (National Research Council - NRC, 2000).

O consumo de pasto foi semelhante para as novilhas em todos os sistemas alimentares, com valor médio de 2,63 $\pm 0,37 \%$ (Tabela 2). Esse consumo similar pode ser explicado pelos valores de 9,41 para relação energia: proteína (NDT:PB) e consumo de $0,38 \%$ do PC de NDT proveniente do suplemento. Os bovinos reduzem o consumo de forragem quando a relação NDT:PB é menor que 7,0 e quando o NDT proveniente do suplemento é maior que $0,70 \%$ do PC (MOORE et al., 1999). Também, novilhas que receberam FAI, com e sem adição de ionóforo, ingeriram, em média, $0,34 \%$ do PC de extrato etéreo, sendo $183,33 \%$ superior ao consumo daquelas que permaneceram exclusivamente em azevém. Ruminantes alimentados com dietas ricas em concentrado podem receber até $6 \%$ de gordura na dieta sem alterar o consumo de MS do pasto (HESS et al., 2008).

O maior consumo de matéria seca total (CMST) foi observado nas novilhas que receberam FAI com adição de ionóforo, sem diferir das novilhas que receberam FAI, que, por sua vez, não diferiram das novilhas que permaneceram exclusivamente em pastagem (Tabela 2). A semelhança no CMST para as novilhas que receberam FAI com ou sem ionóforo

Tabela 2 - Consumo de pasto, total, de fibra em detergente neutro (FDN), proteína bruta (PB) e energia metabolizável (EM) (\% PC) e ganho médio diário $\left(\mathrm{kg} \mathrm{dia}^{-1}\right)$ de novilhas de corte em pastagem exclusiva de azevém ou recebendo farelo de arroz integral, com ou sem adição de ionóforo.

\begin{tabular}{|c|c|c|c|c|c|c|c|}
\hline \multirow{2}{*}{ Sistemas alimentares } & \multicolumn{3}{|c|}{-------------- Períodos de Avaliação ----------- } & \multirow{2}{*}{ Média } & \multirow{2}{*}{$\mathrm{P}^{*}$} & \multirow{2}{*}{$\mathrm{P}^{* *}$} & \multirow{2}{*}{$\mathrm{CV}$} \\
\hline & 03/08-30/08 & 31/08-27/09 & $28 / 09-25 / 10$ & & & & \\
\hline & \multicolumn{7}{|c|}{ 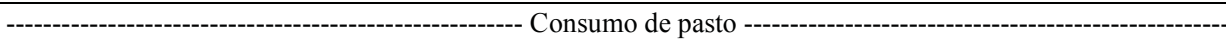 } \\
\hline Azevém & 3,07 & 2,90 & 2,49 & 2,82 & & & \\
\hline Farelo & 2,42 & 2,42 & 2,54 & 2,46 & 0,3836 & 0,3403 & 6,76 \\
\hline Ionóforo & 2,86 & 2,83 & 2,18 & 2,62 & & & \\
\hline \multirow[t]{2}{*}{ Média } & $2,78 \mathrm{a}$ & $2,72 \mathrm{a}$ & $2,40 \mathrm{~b}$ & & 0,0991 & & \\
\hline & & ------- & ---- Consumo & 1 (pasto + & ento) ----. & -----------. & ----- \\
\hline Azevém & 3,07 & 2,90 & 2,49 & $2,82 \mathrm{~b}$ & & & \\
\hline Farelo & 3,22 & 3,22 & 3,34 & $3,26 \mathrm{ab}$ & 0,0764 & 0,3403 & 5,62 \\
\hline Ionóforo & 3,66 & 3,63 & 2,98 & $3,42 \mathrm{a}$ & & & \\
\hline \multirow[t]{2}{*}{ Média } & $3,32 \mathrm{a}$ & $3,25 \mathrm{a}$ & $2,94 b$ & & 0,0991 & & \\
\hline & ----- & - & ------ C & Imo de FL & ---------- & -------- & ------ \\
\hline Azevém & $1,32 \mathrm{a}$ & $1,44 \mathrm{a}$ & $1,11 \mathrm{~b}$ & 1,29 & & & \\
\hline Farelo & $1,27 \mathrm{a}$ & $1,40 \mathrm{a}$ & $1,78 \mathrm{a}$ & 1,48 & 0,2232 & 0,0284 & 7,22 \\
\hline Ionóforo & $1,39 a$ & $1,61 \mathrm{a}$ & $1,63 \mathrm{a}$ & 1,54 & & & \\
\hline Média & 1,33 & 1,48 & 1,51 & & 0,1528 & & \\
\hline Azevém & $0,77 \mathrm{a}$ & $0,53 \mathrm{a}$ & $0,37 \mathrm{~b}$ & $\begin{array}{l}\text { umo de } \\
0,56\end{array}$ & & & \\
\hline Farelo & $0,71 \mathrm{a}$ & $0,52 \mathrm{a}$ & $0,64 \mathrm{a}$ & 0,62 & 0,2251 & 0,0227 & 7,04 \\
\hline Ionóforo & $0,67 \mathrm{a}$ & $0,73 \mathrm{a}$ & $0,60 \mathrm{a}$ & 0,67 & & & \\
\hline Média & 0,71 & 0,59 & 0,54 & & 0,0091 & & \\
\hline Azevém & $16,18 \mathrm{a}$ & $15,61 b$ & $11,57 b$ & $\begin{array}{c}\text { sumo de } \mathrm{E} \\
14,45\end{array}$ & --------. & & \\
\hline Farelo & $16,94 a$ & $16,93 \mathrm{a}$ & $22,11 \mathrm{a}$ & 18,66 & 0,0058 & 0,0163 & 6,88 \\
\hline Ionóforo & $18,35 \mathrm{a}$ & $23,23 a$ & $21,89 \mathrm{a}$ & 21,16 & & & \\
\hline Média & 17,16 & 18,59 & 18,52 & & 0,4945 & & \\
\hline Azevém & 1,07 & 1,11 & 1,05 & lo médio & --------- & 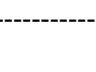 & \\
\hline Farelo & 1,02 & 1,19 & 1,13 & $1,12 b$ & 0,0343 & 0,8060 & 6,20 \\
\hline Ionóforo & 1,31 & 1,43 & 1,33 & $1,35 \mathrm{a}$ & & & \\
\hline Média & $1,13 b$ & $1,24 \mathrm{a}$ & $1,17 \mathrm{ab}$ & & 0,0910 & & \\
\hline
\end{tabular}

* Valores seguidos de letras distintas na coluna indicam diferença pelo lsmeans a 10\% de probabilidade; **Probabilidade da interação sistemas alimentares e períodos de avaliação $(\mathrm{P}<0,10)$; Azevém=novilhas de corte em pastagem exclusiva de azevém; Farelo=novilhas de corte em pastagem de azevém recebendo $0,8 \%$ do peso corporal de farelo de arroz integral (FAI); Ionóforo=novilhas de corte em pastagem de azevém recebendo $0,8 \%$ do peso corporal de FAI $+200 \mathrm{mg}$ animal ${ }^{-1}$ dia $^{-1}$ de monensina. Valores seguidos de letras distintas na coluna e linha indicam diferença pelo Ismeans a $10 \%$ de probabilidade. 
mostra que talvez não tenha sido expressa a vantagem do uso do ionóforo para manter o $\mathrm{pH}$ ruminal em torno de 6,5 (DUFFIELD et al., 2012). Por outro lado, também seria esperado um aumento no CMST com o uso do ionóforo pelo aumento na taxa de passagem e aumento na digestibilidade do conteúdo ruminal (OKINE et al., 1989).

As novilhas que receberam farelo de arroz integral com adição de ionóforo apresentaram $28,67 \mathrm{~g}$ de consumo de suplemento $\mathrm{kg}$ de $\mathrm{PM}^{-1}$, sendo $3,70 \%$ superior em relação às novilhas que receberam apenas FAI $(\mathrm{P}<0,10)$. Foi observado comportamento linear crescente para consumo de suplemento $(\mathrm{g})$ $\mathrm{kg}$ de $\mathrm{PM}^{-1}$ em função dos dias de utilização do azevém $\quad\left(\hat{\mathrm{Y}}=26,02+0,04 \mathrm{x} ; \quad \mathrm{r}^{2}=61,76 \% ; \quad \mathrm{CV}=2,64\right.$; $\mathrm{P}<0,0001)$. Mesmo ao final do período de utilização, o consumo de suplemento por peso metabólico não excedeu o valor limite de $30 \mathrm{~g} \mathrm{~kg}^{-1}$, abaixo do qual não ocorrem alterações no consumo de pasto (HORN \& MCCOLLUM, 1987). Em função da semelhança no consumo de pasto (Tabela 2) pelas novilhas de corte, a taxa de lotação também foi semelhante nos diferentes sistemas alimentares $(\mathrm{P}=0,1909)$, com média de $1089,78 \pm 50,25 \mathrm{~kg}$ de $\mathrm{PC}^{-1}$.

De acordo com o NRC (2000), o consumo de MS para novilhas de corte dessa categoria, considerando um GMD de 1215 gramas, é de 3,42\% do PC. As novilhas que receberam farelo de arroz integral com e sem adição de ionóforo apresentaram o consumo de matéria seca total 2,39\% menor que a exigência prevista. Segundo MERTENS (1994), o consumo de MS é limitado pela repleção ruminal, quando o consumo de FDN kg de $\mathrm{PC}^{-1}$ é superior a $12,5 \mathrm{~g}$ FDN kg de $\mathrm{PC}^{-1}$. O valor médio de $15,10 \mathrm{~g}$ FDN $\mathrm{kg}$ de $\mathrm{PC}^{-1}(\mathrm{P}=0,8769)$ foi observado no presente trabalho, o que causou, provavelmente, redução nos níveis de consumo das novilhas. Por outro lado, animais que recebem suplemento possuem menor tempo de retenção da digesta no rúmen, bem como têm aumentado a frequência das contrações ruminais e a taxa de passagem da digesta (OKINE et al., 1989).

As novilhas ingeriram menor quantidade de MS total no terceiro período de avaliação do pasto (Tabela 2). Esse resultado pode ser explicado em função do menor consumo de pasto ter sido observado no mesmo período de avaliação, pois o suplemento foi fornecido sempre na mesma proporção do PC, durante todo o período experimental. $\mathrm{O}$ ganho médio diário das novilhas que receberam ionóforo adicionado ao farelo de arroz integral foi $22,73 \%$ superior em relação as que permaneceram exclusivamente em azevém ou que receberam farelo de arroz integral (Tabela 2). Melhoria no desempenho animal, associado com a adição de ionóforo em ruminantes, têm sido, em grande parte, atribuída a alterações no metabolismo microbiano ruminal (SPEARS, 1990). O aumento no desempenho dos animais é atribuído principalmente à melhora da eficiência energética, devido ao aumento da produção do ácido propiônico, redução da relação acetato/propionato e diminuição da produção de metano, e também redução nas perdas de aminoácidos que seriam potencialmente fermentados no rúmen (RUSSEL \& STROBEL, 1989).

As novilhas apresentaram ganho médio diário distinto nos diferentes períodos de avaliação do azevém (Tabela 2). No primeiro período de avaliação do pasto, as novilhas apresentaram menor ganho médio diário, mesmo apresentando ingestão de MS semelhante ao segundo período. O número de estações alimentares visitadas por minuto apresentou correlação negativa, com o ganho médio diário no primeiro período $(\mathrm{r}=-0,46 ; \mathrm{P}<0,10)$, o que pode ter ocasionado uma maior demanda energética para o deslocamento, resultando em maior demanda para energia de mantença, mesmo o consumo de pasto sendo semelhante. No último período de avaliação, foi observada redução no ganho médio diário, no consumo de forragem e no consumo total de MS, o que pode ser explicado pela oferta de forragem ter sido limitante ao consumo de pasto nesse período (Tabela 1). Segundo BARGO et al. (2003), o consumo de forragem é limitado quando a oferta de forragem é duas vezes maior que a exigência de consumo de MS dos animais em pastejo.

As novilhas, independentemente do sistema alimentar, apresentaram consumo de fibra em detergente neutro e de proteína bruta semelhante, no primeiro e segundo períodos de avaliação do azevém (Tabela 2). No terceiro período de avaliação, as novilhas que permaneceram exclusivamente em azevém, apresentaram menor ingestão de FDN e PB, em comparação às que receberam suplemento. As novilhas que receberam FAI, mesmo com a redução no consumo de pasto, por meio do consumo de suplemento, puderam manter o consumo de PB e FDN semelhante aos outros períodos de utilização da pastagem.

Novilhas de corte que permaneceram exclusivamente em pastagem apresentaram redução no consumo de energia metabolizável (EM) de $28,49 \%$ do primeiro ao terceiro período de utilização do pasto, o que pode ser explicado pelo aumento no teor de FDN com o avanço do ciclo do pasto (Tabela 2). As novilhas que receberam FAI, com ou sem adição de ionóforo, ingeriram uma quantidade similar de EM no decorrer do ciclo de azevém. Quando o teor de FDN da forragem aparentemente 
consumida aumenta, mais energia é requerida pelos microrganismos ruminais (SAYERS et al., 2003). Quando fornecidos suplementos energéticos às novilhas, mesmo com o aumento no teor de FDN do pasto, o suplemento provavelmente aportou a energia adicional requerida pelos microrganismos ruminais.

\section{CONCLUSÃO}

O fornecimento de farelo de arroz integral, com ou sem adição de ionóforo, para novilhas de corte em azevém, não modifica a ingestão do pasto, fazendo com que a taxa de lotação seja mantida. A adição de ionóforo ao farelo de arroz integral aumenta o ganho médio diário.

\section{COMITÊ DE ÉTICA E BIOSSEGURANÇA}

A pesquisa foi aprovada pelo Comitê de Ética em Pesquisa na Instituição de Origem, protocolada sob no. 012/2012.

\section{REFERÊNCIAS}

ASSOCIATION OF OFFICIAL ANALYTICAL CHEMISTS (AOAC). Official methods of analysis. 16.ed. Arlington: AOAC International, 1995. $1025 \mathrm{p}$.

BARGO, F. et al. Production and digestion of supplemented dairy cows on pasture. Journal of Dairy Science, v.86, n.1, p.1-42, 2003. Disponível em: <http://download.journals.elsevierhealth. com/pdfs/journals/0022-0302/PIIS0022030203735814.pdf $>$. Acesso em: 25 ago. 2012. doi: 10.3168/S0022-0302(03)73581-1.

DUFFIELD, T.F. et al. Meta-analysis of the effects of monensin in beef cattle on feed efficiency, body weight gain, and dry matter intake. Journal of Animal Science, v.90, n.12, p. 4583-4592, 2012. Disponível em: <http://www.journalofanimalscience.org/ content/90/12/4583.full.pdf + html $>$. Acesso em: 10 mar. 2013. doi: 10.2527/JAS.2011-5018.

FRIZZO, A. et al. Suplementação energética na recria de bezerras de corte mantidas em pastagem de inverno. Revista Brasileira de Zootecnia, v.32, n.3, p.643-652, 2003. Disponível em: $<$ http:// www.scielo.br/pdf/\%0D/rbz/v32n3/a16v32n3.pdf $>$. Acesso em: 05 nov. 2012.

HESS, B.W. et al. A decade of developments in the area of fat supplementation research with beef cattle and sheep. Journal of Animal Science, v.86, n.14, p.188-204, 2008. Disponível em: $<$ http://www.journalofanimalscience.org/content/86/14_suppl/ E188.full.pdf + html $>$. Acesso em: 20 ago. 2012. doi: 10.2527/ JAS.2007-0546.

HORN, G.W.; MCCOLLUM, F.T. Energy supplementation of grazing ruminants. In: GRAZING LIVESTOCK NUTRITION CONFERENCE, 1987, Jackson. Proceedings... Jackson: University of Wyoming, 1987. p.125-136.

KOZLOZKI, G.V. et al. Use of chromium oxide in digestibility studies: variations of the results as a function of the measurement method. Journal Science Food Agriculture, v.76, n.3, p.373-
376, 1998. Disponível em: <http://onlinelibrary.wiley.com/ doi/10.1002/(SICI) 1097-0010(199803)76:3\%3C373::AIDJSFA956\%3E3.0.CO;2-Y/pdf>. Acesso em: 20 ago. 2012. doi: 10.1002/(SICI) 1097-0010(199803).

KUNKLE, W.E.; BATES, D.B. Evaluating feed purchasing options: energy, protein, and mineral supplements. In: FLORIDA BEEF CATTLE SHORT COURSE, 1998, Gainesville. Proceedings... Gainesville: University of Florida, 1998. p.59-70.

MERTENS, D.R. Regulation of forage intake. In: FORAGE QUALITY, EVALUATION, AND UTILIZATION, 1994, Madison. Proceedings... Madison: American Society of Agronomy, Crop Science Society of America, Soil Science Society of America, 1994. p.450-493.

MOORE, J.E. et al. Effects of supplementation on voluntary forage intake, diet digestibility, and animal performance. Journal of Animal Science, v.77, n.S2, p.122-135, 1999. Disponível em: $<$ http://www.animal-science.org/content/77/suppl_2/122.full. pdf>. Acesso em: 05 set. 2012.

NATIONAL RESEARCH COUNCIL (NRC). Nutrient requeriments of beef cattle. Washinton, D.C. 2000. 249p.

OKINE, E.K. et al. Effects of changes in frequency of reticular constractions on fluid and particulate passages rates in cattle. Journal of Animal Science, v.67, n.12, p.3388-3396, 1989.

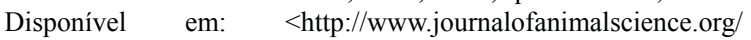
content/67/12/3388.full.pdf+html>. Acesso em: 10 set. 2012.

ØRSKOV, E.R.; MCDONALD, I. The estimation of protein degradability in the rumen from incubation measurements weighed according to rate of passage. Journal Agricultural Science, v.92, n.2, p.499-503, 1979.

POND, K.R. et al. Passage of chromium-mordanted and rare earthlabeled fiber: time of dosing kinetics. Journal Animal Science, v.67, n.4, p.1020-1028, 1989. Disponível em: <http://www. journalofanimalscience.org/content/67/4/1020.full.pdf + html $>$. Acesso em: 22 set. 2012.

ROBERTSON, J. B.; VAN SOEST, P.J. The detergent system of analysis. In: JAMES, W. P.T.; THEANDER, O. (Eds.). The analysis of dietary fibre in food. New York: Marcel Dkker, 1981. Chapt.9, p.123-158.

ROSA, A.T.N. et al. Consumo de forragem e desempenho e novilhas de corte recebendo suplementos em pastagem de azevém. Ciência Rural, v.43, n.1, p.126-131, 2013. Disponível em: $<$ http://www.scielo.br/pdf/cr/v43n1/a2513cr5959.pdf $>$. Acesso em: 10 fev. 2013.

RUSSEL, J.B.; STROBEL, H.J. Minireview. Effect of ionophore on ruminal fermentation. Applied Environmental Microbiology, v.55, n.1, p.1-6, 1989. Disponível em: <http://www.ncbi.nlm.nih. gov/pmc/articles/PMC184044>. Acesso em: 19 out. 2012.

SAYERS, H.J. et al. The effect of level and type of supplement offered to grazing dairy cows on herbage intake, animal performance and rumen fermentation characteristics. British Society of Animal Science, v.76, n.3, p.439-454, 2003.

SPEARS, J.W. Ionophores and nutrient digestion and absorption in ruminants. Journal of Nutrition. v.120, n.6, p.632-638, 1990. Disponível em: <http://jn.nutrition.org/content/120/6/632.full. pdf + html $>$. Acesso em: 10 out. 2012. 